\title{
A questionnaire survey approach to the study of the psychosocial consequences of shiftwork
}

\author{
MICHAEL J. SMITH and MICHAEL J. COLLIGAN \\ National Institute for Occupational Safety and Health, Center for Disease Control \\ Public Health Service, U.S. Department of Health Education and Welfare \\ Cincinnati, Ohio 45226 \\ and \\ DONALD L. TASTO \\ Tasto Associates, Palo Alto, California 94305
}

\begin{abstract}
A questionnaire survey of shiftworkers, while somewhat less objective than a health and safety records evaluation or a medical study, can provide a fast and efficient way for collecting a large amount of detailed data about the psychological, social, and health consequences of shiftwork. In fact, this method can produce information that cannot be derived from either of the other two techniques. Measures of the many diverse and subtle factors relating shiftwork and health, such as personal adjustment, personality characteristics, and social adjustment, can be evaluated using a questionnaire; the other methods are insensitive to these factors. This paper provides a description of a questionnaire survey study of the psychosocial factors in shiftworker health and a discussion of the most appropriate techniques to use in conducting this type of survey. The relative merits of a questionnaire survey vs. other data collection methods are also discussed.
\end{abstract}

Psychological research on shiftwork typically focuses on job attitudes. The findings indicate generally that attitudes vary as a function of numerous interacting variables, for example, type of work, skill level required, type of industry, length of time on the job, characteristics of workers' communities, and general needs and demands.

Investigators have documented both positive and negative attitudes toward shiftwork. Wedderburn (1967) found that $53 \%$ of the men on a rapidly rotating shift liked shiftwork, and 15\% disliked it. Blakelock (1967) found that $57 \%$ of the rotating shiftworkers in an oil refinery liked shiftwork; 12\% disliked it. Taylor (1967) reported greater job satisfaction among nonday shiftworkers than among day shiftworkers.

On the other hand, shiftwork is described by Banks (1956) as "resignation rather than adaptation" and by Downie (1963) as "acceptance rather than acclaim." Ulich (1957) found that 67\% of a population of German shiftworkers expressed negative attitudes toward shiftwork; over $50 \%$ of a different sample of shiftworkers and their wives had negative attitudes (Bast, 1960).

There appear to be various psychosocial consequences of shiftwork, including increases in irritability, nervousness, anxiety, fatigue, and bad tempers (Mott, Mann, McLoughlin, \& Warwick, 1965; Ulich, 1957; Smith, Melton, \& McKenzie, Note 1), as well as diminished self-esteem and heightened feelings of conflict and pressure (Mott et al., 1965). Family and life disturbances have been noted (Banks, 1956; Bast, 1960; Mott et al., 1965; Uich, 1957), along with negative effects on shiftworker social life (Bast, 1960; Blakelock, 1967; Mann \& Hoffman, 1960; Mott et al., 1965). The ability to adjust to shiftwork appears to be related to worker personality (Bast, 1960; Ostberg, Note 2) and family attitudes toward work (Bast, 1960; De la Mare \& Walker, 1968; Mann \& Hoffman, 1960).

While a number of studies have defined a variety of psychosocial problems associated with shiftwork, few have been conducted in the United States. A comprehensive study by Mott ct al. (1965) related a number of psychosocial factors to possible health problems. A second more encompassing study (Tasto, Colligan, Skjer, \& Polly, Note 3) related self-reported health status and accident information to a variety of psychosocial factors defined as possible shift problem areas. This paper deals with just one aspect of the Tasto et al. (Note 3) study, which encompassed a literature and survey effort to define the shiftwork population in the United States, a health and safety records evaluation of various shift regimens, and a questionnaire survey of shiftworkers to evaluate possible health and safety aspects of various shift systems. This paper deals only with the instruments and methods used to collect the self-report data from the shiftworkers studied. 


\section{DESCRIPTION OF THE SURVEY METHODS}

\section{Industry and Sample Selection}

After investigating a number of major industries in which shiftwork was significant, Tasto and Colligan (Note 4) selected the food processing industry and hospital/health care delivery (nursing) for further study. These two areas were chosen not only because of their large numbers of shiftworkers, but also because they represent varying work operations with stable shift patterns. Food processing employed about 593,000 shiftworkers; hospital/nursing employed about 1,117,000. A sample of 1,200 workers from each industry was selected for surveying. The sample was stratified by shift schedule (day, aftemoon, night, rotating) in equal proportions. The sample was selected in an attempt to define major shiftwork problems that could be evaluated by more definitive future research.

\section{Questionnaire Instrument}

One of the most significant aspects of this study was the development of a comprehensive questionnaire instrument for surveying shiftworkers. To our knowledge, this questionnaire represents the most comprehensive battery of items ever developed for examining the relationship of health and personal adjustment to shiftwork. It includes the following components. (1) Background information: age, sex, ethnic background, marital status, height, weight, income, number of household members. (2) Personal habits: alcohol consumption, smoking, sexual behavior. (3) Lifestyle: social support, social life, child rearing difficulties, recreational activities. (4) Job information: job duties, tenure, overtime work, supervisory interaction, work group interaction. (5) Health status: selfrating of overall health and of spouse's overall health, recent hospital visits, medication usage, symptom frequency check list, major disease states, abbreviated family health history, recent work-place accidents, and female menstrual problems. (6) Psychological status: profile of mood states (POMS), which measures anxiety, tension, depression, anger-hostility, vigor, fatigue, and confusion; and the Eysenck personality inventory (EPI), which measures extroversion and neuroticism. (7) Sleep patterns: quality and quantity of sleep, satisfaction with sleep, shift interference, and sleep medication usage. (8) Eating patterns: food consumption patterns, appetite, snacking, shift interference. (9) Shift schedule: type of schedule; shiftwork history; rotational pattern; tenure on shifts; satisfaction with shift schedule; and interference with health, personal habits, sleeping, eating, social life, and child rearing.

The questionnaire consists of over 300 separate items to be answered by the shiftworker. Most are instant response items, so that the time to complete the questionnaire is about $50-60 \mathrm{~min}$. The questionnaire was pretested to determine items that were of little value in discriminating shiftwork problems. The final version that was used in the survey contained only those items that provided adequate discrimination in the pretest.

\section{Surveying Procedures}

Getting organizations to cooperate in a study such as this can be difficult, especially when the survey is tied to a health and safety records evaluation at each of the sites of interest. Accessing health and safety records is a sensitive issue with most companies, due to concerns for employee privacy and company liability. The approach taken for obtaining participants was to contact national organizations to which the desired companies belonged, such as the National Canners Association, to try to enlist their aid and support. This was successfully accomplished for both the food processing and nursing areas. After approximately 4 months of continuous effort, consent to conduct the study was obtained from 10 hospitals and 8 food processing plants.

Once consent was obtained, a site visit was undertaken to explain the purpose of the study and the procedure to be followed to the plant managers and hospital administrators. This debriefing typically consisted of a discussion of the shiftwork literature pertaining to possible health, safety, and psychosocial effects, a presentation of the procedures to be followed in conducting the health and safety records evaluations and the questionnaire survey, a discussion of Privacy Act requirements and subject confidentiality, the requirements for subject informed consent, and an explanation of the types of reports to be developed from the data.

After discussion of these issues, agreement was reached on the conduct of the survey at each site. A follow-up letter was sent to the manager or administrator of each site to confirm the agreement in writing. At each meeting for the food processing plants, the union plants were asked to have the union represented; each company complied with this request. Nursing staffs did not have unions.

Arrangements to administer questionnaires in the 18 different sites were initiated by first contacting the personnel officer and obtaining a list of employees' names and home addresses, categorized by shift and job type. Using a table of random numbers, a sample from each list was compiled that totaled to approximately 2,400 shiftworkers.

Each prospective participant was mailed a packet containing a cover letter briefly describing the project, a questionnaire survey form, a large postpaid retum envelope, and a small envelope attached to the front page of the questionnaire, to be used to send each respondent $\$ 5$ for filling out the questionnaire.

As completed questionnaires were received, the site 
and shift category of the respondent, but not the name, was coded on the first page. The small envelope was then detached, a check was enclosed, and the envelope was mailed. Once this was completed, there was no way to match a respondent to a particular questionnaire, thus insuring complete anonymity and privacy. As the questionnaires were received, a check of response rate for each site was kept for follow-up if the initial response rate was insufficient.

\section{DISCUSSION}

Certain aspects of the methodology were not based on experimental or statistical necessity, but on the realities of conducting a field research study. This discussion deals with the issues raised by such realities and their impact on this type of research.

\section{Measurement Instrument}

The survey questionnaire was designed to elicit basic information about employee perceptions of work schedule, social and family life, and health. As such, a broad range of information was tapped. Only items shown to have been of significance by past research were included in the original survey instrument. This instrument was then pretested, and only those items that showed discriminating value in defining shiftworker problems were included. These procedures allowed for a sufficient amount of detail for the items of interest, while keeping the questionnaire length at a minimum.

The length of the questionnaire is very important. Typically, management will not make work time available for surveys because of the cost involved. In this study, about $2,000 \mathrm{~h}$ of survey time would have been needed at an approximate hourly rate of $\$ 8-\$ 10$. When permission is sought for a survey to be conducted during working hours, the survey instrument must be extremely short, probably too short to adequately tap all of the variables of interest. Therefore, in a typical survey, workers are most likely to be asked to fill out their questionnaires at home. If the take-home questionnaire requires much longer than $1 \mathrm{~h}$ to complete, it takes a very strong motivator to obtain adequate subject participation, and even then, the response rate is typically low (less than $50 \%$ ).

Even when the questionnaire takes less than $1 \mathrm{~h}$ to complete, a motivator is often necessary to obtain an adequate response. In this study, participants were paid $\$ 5$ for filling out and returning the questionnaire. Since it took about $1 \mathrm{~h}$ to complete, this compensation was somewhat less than the hourly work rate of pay, but adequate enough to motivate a reasonable response (over $60 \%$ of those surveyed responded on the first and only round of surveying). Even though the issues involved in this study were significant to the workers, their health and welfare, previous research has shown that this is not a sufficient inducement to insure an ade- quate response. Therefore, the significance of providing a motivator to respond is critical to a successful survey.

The validity of questionnaire items is also significant, because the credibility of the study in the eyes of managers and administrators of work establishments, as well as union officials, most often rests with the content of the questionnaire. Items that can be corroborated by previous research are viewed much more positively than items that comprise a "fishing expedition" and are lacking in a research or logic base. Such uncorroborated items cast suspicion on the intent of the research and many times are the primary reason companies decide not to participate in a study. Therefore, limiting the questionnaire to verified problem areas and to those items showing discriminating value not only keeps the length of the questionnaire reasonable, but also increases the credibility of the study for management and unions.

Another important aspect of credibility deals with the development of specific hypotheses that are evaluated after data collection. These hypotheses stand as the endpoint of a study, the goals that the researcher is striving to achieve. In a very explicit, summary fashion, they tell the employers and unions just what the study is all about and how it might impact them. One of the most significant problems with survey research is that clear-cut hypotheses are not always developed before data are collected. Many times, the data are statistically "massaged" at the end of a study to generate findings without having specific hypotheses tested. Such findings may have little meaning to those persons affected by the results, and therefore, these persons may be reticent to participate in such an endeavor. In addition to helping study credibility, hypotheses also allow the managers and unions to determine if the specific data being collected are adequate to test the hypotheses. If both are in concert, it is easier to gain agreement to participate.

\section{Gaining Consent and Cooperation}

All of our contacts with participating places of work included both management and unions, where applicable. Even though this survey was not conducted at work sites, it was important to have both management and labor participate. For parts of this study, worker names and addresses could have been obtained from the union, and the management need not even have been notified. However, if the study results are to be utilized to their fullest, it is necessary to have management involved. The same is true of the union.

One of the problems with working with all in terested groups in such a study is that each has to review the study protocol and questionnaire instrument, and inevitably, each suggests "improvements," which can produce quite a problem. However, if the hypotheses are specified clearly, and the questionnaire items are meaningful and have research corroboration, these "improvements" can usually be dealt with easily. 
As indicated earlier, a written agreement concerning study procedures for each work site was sent to both the management and the union. Agreement to this understanding was obtained, most often by a letter from the plant manager and chief local union official, before the survey was undertaken. This eliminated the possibility of any misunderstanding or complaints of improper procedure once the study was underway. Such a procedure also commits the plant to carry through with the study until completion.

\section{Representativeness of the Data}

One of the most often discussed issues dealing with surveys is the representativeness and generalizability of the data collected. This reflects on the validity of the survey instrument, the sampling methods used, the stratification of the sample by critical variables, and the response rate of the subjects. The significance of each of these to the interpretation of the data is obviously not equivalent. The most sophisticated sampling and stratification methods can be used, but if the survey instrument is faulty, then the results are suspect. The same is true with response rate. If the response rate is inadequate, then the sampling plan is of little value. Of course, if the response rate is high but the original sample or the stratification is inadequate, then the conclusions that can be drawn are limited. Therefore, it is necessary to balance these factors in order that the study findings have meaning.

Balance depends on the specificity of the hypotheses to be tested. It is very important to have highly specific hypotheses. This requirement above all others is important for an in-plant work place questionnaire survey study. The other requirements depend on the respondent population to be evaluated. In the study examined in this paper, the respondents were stratified by industry type and shift regime. Variables such as age, sex, and area of the country were not used as stratifiers, even though they were considered as significant variables that could impact the study results. The number of respondents was large enough (over 1,900 ) that these important variables could be statistically evaluated and controlled. Therefore, the need to further stratify the survey distribution was unnecessary. Indeed, such further stratification would have greatly complicated questionnaire distribution and collection.

The sampling plan for this study was not based on the expected variability of critical measures, but on financial considerations. The cost of surveying more than 2,400 workers could not be justified solely on statistical grounds. Consequently, approximately 1,200 workers for each industry were surveyed. The response rate of the survey of over $60 \%$ produced usable data from 1,934 workers, the largest pool of questionnaire survey data on any group of shiftworkers ever collected in the United States. As such, the results of the study have great significance for evaluating the psychosocial aspects of shiftwork, even though the sampling plan was not optimal. Unfortunately, field studies many times preclude the use of the most desirable survey sampling methods. However, this in no way should depreciate the results of these studies, but rather, should temper the conclusions that are drawn.

\section{Methods of Distribution and Collection}

The workers were apprised of the study upon receiving the questionnaire packet. The packet contained a cover letter that very generally described the purpose of the study and indicated that both management and union (if applicable) endorsed the study and solicited the workers' participation. Anonymity was guaranteed, and the respondent was informed that he or she would be paid $\$ 5$ upon returning a completed questionnaire. This method produced an initial 60\% response rate, but it is not the preferred method of distributing and collecting questionnaires. A more effective method would be to have on-site distribution and collection of the survey questionnaires. Such an approach requires a short meeting with employees at each work site to describe the purposes of the study, and to explain the techniques for insuring subject anonymity, as well as the motivational program. This meeting can be a general assembly or small group "get-togethers," depending on the plant facilities and availability of employees during working hours. This sort of meeting allows employees to ask questions about the study. Both management and union (if applicable) should attend the meeting and indicate support. Questionnaire packets can be handed out at the end of the meeting. The surveying team stays on-site for 1 or 2 days to collect the surveys from the employees and to answer more specific questions. Those not returning surveys are asked to mail them in via a postpaid envelope. Payment is made in the same manner as in the mail-out survey. This approach allows for a "personal" touch that enhances employee desire to participate. It also relates the survey to the work place and makes it more realistic and less "research-like" to the employee. Such an approach can enhance response rate considerably.

\section{COMPARISON OF A QUESTIONNAIRE SURVEY APPROACH TO OTHER APPROACHES}

Questionnaire survey studies of shiftwork can provide advantages over other types of approaches, such as interview surveys, records studies, clinical evaluations, or laboratory studies. A primary advantage is that the questionnaire survey can collect data from a large number of persons for a relatively low cost per person. Compared to the records evaluations method for collecting data, the survey questionnaire has the advantages of (1) collecting more current data, (2) being able to examine a host of variables not found in health, safety, or personnel records, (3) providing easier access 
to data, and (4) providing data that are more consistent from one source to another. However, while the data are more consistent, they are less objective than records data, since they are based on self-report. The subjectivity of the self-report data is one of the greatest weaknesses of a questionnaire survey. That is why the study described here used two different methods to collect data on the same subject pool: health and safety records evaluation, and a questionnaire survey. Each method can be used to verify the other.

The overriding advantage of a questionnaire survey over a records study lies in the diversity of information that can be collected. Records data are greatly limited in the number of different variables that can be explored. Such factors as shiftwork effects on family life, child rearing, social activities, and aspects of worker psychological status and personality cannot be obtained from work-place records and most likely would not be available from other record sources. The questionnaire survey, on the other hand, is only limited in the number and variety of variables that can be examined by practical matters, such as limiting the length of the questionnaire and keeping the items to verified areas of concern. While it is true that the same information can be collected using interviews rather than questionnaires, the greater relative efficiency of the questionnaire and the lower cost per respondent makes this the preferred method when dealing with highly defined variables of interest. When the variables are poorly defined and the verifying data are not available, then the in tervie w allows for more detailed probing, which is necessary to obtain satisfactory information. This, of course, limits the sample size and, therefore, the generalizability of the data.

Finally, the questionnaire survey allows for the collection of a great deal of data from a large number of respondents, which gives added power to statistical evaluations of the data. Even when variables such as agc or sex are not stratified into a questionnaire distribution plan, the massive data base that can be collected guarantees an abundance of information on all variables of interest that can be evaluated and controlled statistically after the data have been collected. This type of statistical control, while no substitute for appropriate sampling, does allow for greater generalization of the data collected.

\section{SUMMARY}

This paper has dealt with the relative advantages of a questionnaire survey of psychosocial factors and health, using an actual study as an example of strengths and weaknesses of such an approach. The questionnaire survey allows for the collection of a wide diversity of information from a large group of subjects for a relatively low cost per subject. The major limitation is the subjective nature of the data and biases that can be introduced by respondents. These problems can be dealt with by combining questionnaire surveys with more objective methods, such as records evaluations, to obtain verification and corroboration of findings.

\section{REFERENCE NOTES}

1. Smith, R. C., Melton, C. E., \& McKenzie, J. M. Affect adjective checklist assessment of mood variations in uir traffic controllers. FAA Office of Aviation Medicine Report No. 71-21, 1971.

2. Ostberg. O. Interindividual differences in circadian fatigue problems of shift workers. Report No. 1972:24 of the Laboratory of Environmental Hygiene and Ergonomics, Stockholm, Swedish Cooperative Union and Wholesale Society, 1972.

3. Tasto, D. L., Colligan, M. J., Skjei, W. W., \& Polly, S. J. Health consequences of shift work. DHEW (NIOSH) Publication No. 78-154, 1978.

4. Tasto, D. L.. \& Colligan, M. J. Shift work practices in the United States. DHEW (NIOSH) Publication No. 77-148, 1977.

\section{REFERENCES}

Banks, 0 . Continuous shiftwork: The attitudes of wives. Occupational Psychology, 1956, 30, 69-84.

BAST, G. H. Ploegenarbeid in de Industry Contractgroepvoering Productivitieit. Arnkem: Van Loghum Slaterus, 1960.

DE la MARE, G., \& WALkER, J. Factors influencing the choice of shift rotation. Occupational Psychology, 1968, 42, 1-21.

DownIE, J. H. Some social and industrial implications of shiftwork. London: Industrial Welfare Society, 1963.

Mann, F. C., \& Hoffman, L. R. Automation and the worker. New York: Holt, 1960

Mott, P. E., Mann, F. C., McLoughlin, Q., \& Warwick, D. P. Shiftwork: The social. psychological and physical consequences. Ann Arbor: University of Michigan Press, 1965.

TAYLOR, P. J. Shift and day work: A comparison of sickness absence, lateness and other absence behavior at an oil refinery from 1962 to 1965. British Joumal of Industrial Medicine, 1967, 24, 93-102.

Utich, E. Zur Frage der Belastung des Arbeitenden Menschen durch Nacht und Schicktarbeit. Psychologische Rundschau, 1957, 8, 42-61.

WEDDERBURN, A. A. I. Social factors in satisfaction with swiftlyrotating shifts. Occupational Psychology, 1967, 41, 85-107. 